\title{
Innovaatiotalouden moderni/koloniaalisuus
}

\author{
ANTTI TARVAINEN
}

Innovaatiotaloudella ja kolonialismilla vaikuttaisi ensisilmäyksellä olevan hyvin vähän tekemistä keskenään. Innovaatiot assosioituvat Schumpeteriin, Piilaaksoon ja digitaalisiin teknologioihin - kolonialismi purjeveneisiin ja Kolumbukseen. Esitän tässä kirjoituksessa, että kolonialismintutkimus tarjoaa hedelmällisiä lähtökohtia innovaatiotalouden ymmärtämiseen. Anibal Quijanon käsite moderni/koloniaalisuus on yksi toimiva tapa jäsentää innovaatiotalouden ja kolonialismin suhdetta.

Perulaisen sosiologi Anibal Quijanon mukaan moderni on kuvittelun ja materiaalisten suhteiden verkko, jota määrittää koloniaalisuus - eurooppalaisen kolonialismin tuottama kuva maailmasta. Tästä näkökulmasta maantiede jakautuu aktiiviseen Eurooppaan ja passiiviseen tai barbaariseen itään ja etelään, aika eurooppalaisten eliittien edustamaan edistykseen ja ei-Euroopan edustamaan esihistoriaan tai stagnaatioon, $k e$ hot värin ja sukupuolen mukaan koodattuihin hierarkioihin. Quijano ja muut keskeiset dekolonisaation teoreetikot esittävätkin, että kolonialismin myötä levinneet tavat tuottaa todellisuutta jatkuvat osana nykyaikaisia edistyksen projekteja (Dussel 1993; Mendieta 2001; Quijano 2007). Tätä modernin ja kolonialismin kytköstä Quijano kuvaa käsiteparilla moderni/koloniaalisuus. Kulttuurisesti moderni/koloniaalisuus tarkoittaa "mielikuvituksen kolonisaatiota" sellaisen kuvittelun tavan leviämistä, jossa "Eurooppa" ja "eurooppalaiseksi" ymmärretty keho kantaa tilan ja ajan hierarkioita mukanaan (Mendieta 2001; Quijano 2007, 169). Materiaalisesti moderni/koloniaalisuus tarkoittaa kehojen ja alueiden muuttamista työvoimaksi ja resursseiksi eurosentristen koodien mukaisesti - siten että ne palvelevat dominoivia alueita ja ryhmiä. Quijano on työssään painottanut luokan ja "rodun" yhteyttä, kun taas koloniaalisuuden käsitettä jatkokehittäneen Maria Lugonesin ajattelussa kiinnitetään aiheellisesti huomiota myös "sukupuolen" koloniaalisuuteen.

Koloniaalisuuden käsite haastaa ja jatkaa kriittisen teorian perinnettä kapitalismin edistysvisioiden syväanalyysissä. Koloniaalisuus, kuten Adornon ja Horkheimerin valistuksen dialektiik$k a$, kiinnittää huomion modernin edistyksen väkivaltaiseen ja totalitaristiseen varjoon. Eurooppalaisen totalitarismin sijaan koloniaalisuus tuo esiin modernin kolonialistiset tendenssit, ja luo siten Frankfurtin koulukunnan kriittistä teoriaa globaalimman viitekehyksen kapitalismin edistysvisioiden tutkimiseen. (Challand \& Bottici 2021, Kerner 2018.) Edistystä ja kolonialismia ei tästä näkökulmasta käsin voida siis erottaa toisistaan.

Tässä esseessä haluan hyödyntää moderni/koloniaalisuus käsiteparin avaamaa kriittistä tarkastelutapaa kapitalistisiin edistyksen visioihin. Eri- 
tyisesti keskityn innovaatiotalouden analyysiin. Innovaatiotaloudella viittaan korkean teknologian, riskisijoittajien, startup-yrittäjien ja teknologiayhtiöiden muodostamaan kenttään, jonka taloudellisena ja kulttuurisena keskuksena toimii Piilaakso. Innovaatiotalous voidaan nähdä kapitalismin sisältä nousevana käsitteenä, jonka kautta maantiedettä ja ihmisryhmiä jaotellaan immateriaaliseen/materiaaliseen talouteen, teolliseen/jälkiteolliseen aikakauteen, ja korkeaan/matalaan teknologiaan ja osaamiseen. Todellisuudessa, nämä jaottelut eivät ole päteviä: Piilaakson riskisijoittajien ja digitaalisten innovaatioiden ohella myös Kongon koltaanikaivokset, Applen alihankkijoiden kokoonpanotehtaat Kiinassa ja Amazonin matalapalkkaiset työntekijät kuuluvat innovaatiotalouteen. Näkymättömyydellä on koloniaalisuuden näkökulmasta systeeminen funktio: se piilottaa väkivaltaa ja mahdollistaa edistyksen vaatteisiin pukeutuvia laajenemisen ja valloittamisen prosesseja. Tarkastelenkin innovaatiotaloutta juuri kolonialistisen näkymättömäksi tekemisen ja valloittamisen näkökulmasta. Essee pohjaa Globalizations-lehdessä julkaistavaan tutkimusartikkeliini (Tarvainen 2021), jossa tutkin innovaatiotalouden aikakäsityksiä innovaatiotalouden keskeisen kirjallisuuden kautta. Nostan tässä esseessä esiin keskeisiä tapoja, joilla moderni/koloniaalisuus esiintyy kyseisessä kirjallisuudessa. Yhteenvedossa ehdotan, että innovaatiotaloutta on hedelmällistä tutkia kolonialismin tutkimuksen keinoin. Tällöin innovaatiotalous asettuu osaksi pidempää historiallista kaarta ja siihen kytkeytyvät globaalit väkivallan muodot tulevat esiin.

\section{Innovaatiotalouden näkymättömät historiat}

Nykyaikaiset mielikuvat innovaatioista ja innovaatiolähtöisestä kasvusta pohjaavat voimakkaasti Joseph Schumpeterin luovan tuhon metaforaan eli ajatukseen siitä, että yhteiskunta ja talous etenee hyppäyksittäin riskisijoittajien ja yrittäjien synnyttämien innovaatioiden kautta (Daub 2020; Geiger 2019). Piilaakso, kuten Appadurai ja Alexander kirjoittavat, ilmentää "Schumpeterin paluuta" kapitalismin edistysvisioiden keskiöön
(2020, 45). Ymmärtääksemme innovaatiotaloudessa leviäviä myyttejä meidän on siis ensiksi pureuduttava Schumpeterin ajatteluun.

Useat tutkijat ovatkin käsitelleet sitä, kuinka Schumpeterin uraauurtava näkemys talouden kehityksestä rakentuu eurosentriselle perustalle (Ghazanfar 1995; Hosseini 2003). Schumpeterin ehkäpä kuuluisimman kirjan Capitalism, Socialism and Democracy (1943/2003) luku The Civilization of Capitalism on hyvä paikka aloittaa luovan tuhon historiakäsitykseen tutustuminen. Schumpeterille maailma jakautuu historiaa eteenpäin vievään eurooppalaiseen porvaristoon ja Euroopan ulkopuolella oleviin "modernieihin primitiiveihin", jotka elävät yhä kuin "50 000 vuotta sitten" (Schumpeter 2003, 121). Saman sivun alaviitteestä selviää, että Schumpeter pohjaa käsityksensä ennen kaikkea ranskalaisen antropologi Lucien Lévy-Bruhlin tutkimuksiin. Schumpeter viittaa vielä erikseen ammentavansa Lévy-Bruehlin arkkityyyppisen kolonialistisista tutkimuksista ${ }^{1}$, joiden tavoitteena oli avata eurooppalaisille muiden, "alempiarvoisten" ja "primitiivisten" yhteiskuntien mielen ja sielun mekaniikkaa (Bernasconi 2005; Betts 1982, 66-77).

Seuraten ajalleen tyypillistä eurosentristä tarinaa sivilisaation noususta (vom mythos zum logos), Schumpeter sijoittaa taloudellisen ajattelun alkupisteen antiikin Kreikkaan, "Euroopan" kuviteltuun alkukotiin (Bottici 2009). Esimerkiksi Schumpeterin History of Economic Analysis kirjassa esittämä taloustieteellinen evoluutio "alkaa antiikin Kreikasta" kunnes "kreikkalais-roomalaisen maailman" katoamisen myötä häviää ihmiskunnan historiasta palaten vasta 1200 -luvun latinankielisten skolastikkojen myötä (Schumpeter 1954, $8,52)$. Kreikkalais-roomalaisten ja skolastikkojen välissä on Schumpeterin mukaan noin 500 vuotta "tyhjiä vuosisatoja", jolloin ei oikeastaan tapahtunut mitään (Demir \& Kaboub 2009; Schumpeter 1954, 52, 74). Esimerkiksi Islamilaisen sivilisaation ja arabikulttuurien kontribuutiot ${ }^{2}$ taloustieteelliseen ajatteluun, matematiikkaan (kuten algebra ja algoritmit) tai "kreikkalaiseen" filosofiaan eivät siis kuulu luovan tuhon evolutionääriseen kertomukseen (Ghazanfar 1995). Se tosiasiallinen vuorovaikutus ja taloustieteellinen kehitys, jota esi- 
merkiksi Islamilaisen, juutalaisen ja kristillisen maailman sisällä on Schumpeterin "kadonneina vuosisatoina" ollut, jää siis Schumpeterin evoluution ulkopuolelle (Bernardelli 1961, 320). Eurooppa on Schumpeterille historian lähde, "Aasia" puolestaan edustaa passiivisuutta.

Tämä Schumpeterille tyypillinen innovaatioiden linkittäminen osaksi "Euroopan" tarinaa ja muiden "sivilisaatioiden" roolin poispyyhkiminen jatkuu myös Piilaaksoa ja innovaatioita käsittelevässä nykykirjallisuudessa. Esimerkiksi Piilaakson historiaa käsittelevässä kirjallisuudessa Piilaakson tarina aloitetaan lähes poikkeuksetta joko 1900-luvun alusta tai 1940-1950-luvuilta, jolloin Yhdysvaltojen puolustusteollisuus alkoi investoida tutkimus ja kehitystoimintaan alueella (Berlin 2017; O’Mara 2019; Saxenian 1983). Historioitsija Margaret O'Mara toteaa uudessa Piilaakson historian "lopullisesti yhteenvetävässä" kirjassaan (2019), että Piilaakso oli kuin luotu innovaatiotalouden keskittymäksi, sillä ennen toista maailmansotaa alue oli vain "tyhjää", kartoittamatonta" ja "nuorta" maata (2019, 67, 110-112, 398-401). Kuitenkin juuri ne "hubit", jotka Piilaakson historiaa käsittelevä kirjallisuus usein nostaa Piilaakson syntypaikoiksi (kuten Standfordin yliopiston ja Moffettin avaruuskentän) sijaitsevat alkuperäiskansojen pakkotyökeskusten ja heiltä varastetun maan päällä (Spencer 2018). Samaan aktiiviseen unohtamisen historiaan osallistuu myös Thomas P. Hughes, ehkäpä Yhdysvaltojen kuuluisin teknologiahistorioitsija. Pulitzer-ehdokkaana olleessa American Genesis teoksessa (2020) Hughes esittää, kuinka amerikkalaisten siirtokuntien pyrkimys "luonnontilan valloittamiseen" (state of nature) ja korvaamiseen "teknologiantilalla" (state of technology) loi pohjan erityiselle amerikkalaiselle energialle, joka lopulta johti informaatioteknologian ja Piilaakson vallankumoukseen $(2020,294)$. Alkuperäiskansojen kulttuurien, teknologioiden, taloudellisten verkostojen ja kotien sijaan Hughes näkee kolonisaatiota edeltäneessä Piilaaksossa vain koskematonta, esiteknologista luontoa, joka voidaan (kolonisaation avulla) jalostaa korkeakulttuurin raakaaineeksi. Piilaakson informaatiovallankumous, Hughes täsmentää, on "Periklean runonlausun- nan, renesanssin taiteilijoiden, Weimarin arkkitehtien ja brittiläisen teollisen vallankumouksen" historiallinen perillinen eli eurooppalaisen sivilisaation jatke $(2020,13)$. Sivumennen sanottuna Hughesin tarina luonnon muuttamisesta teknologiaksi toistaa Amerikan haltuunoton tärkeimmän filosofin eli John Locken ajatusta, jonka mukaan alkuperäiskansojen maan haltuunotto on oikeutettua, mikäli haltuunotto parantaa tuottavuutta eli, Locken ajattelussa, palvelee koko yhteiskuntaa (Fields 2017).

Alkuperäiskansoille käy siis näissä Piilaaksokirjallisuuden esimerkeissä samoin kuin Schumpeterin islamilaiselle maailmalle: ne häviävät innovaatioiden kuvitellusta historiasta. Innovaatiotalouden kirjallisuus jatkaakin asuttajakolonialistista "tyhjän maan" fantasian perinnettä, jossa alkuperäiskansojen historia ja toimijuus painetaan unholaan progressiivisten tarinoiden tieltä (Veracini 2008). Psykologisesta näkökulmasta "tyhjän maan" fantasian tehtävänä on lievittää asuttajakolonialismiin kuuluvaa ahdistuneisuutta, joka syntyy alkuperäiskansojen kotien ja omistusoikeuksien väkivaltaisesta hävittämisestä (Ramirez 2007; Veracini 2008). Hughesin esimerkki Piilaaksosta Periklean runolausunnan jatkeena kuvaa hyvin myös sitä, kuinka Piilaakso amerikkalaisessa keskustelussa asettuu osaksi euroamerikkalaista sivilisaationarratiivia tai kuten bisneshistorioitsija Stuart Leslie hehkuttaa, tarjoaa oppitunnin siitä, "kuinka Länsi voitettiin" (1993). Startup-ikoni Peter Thiel osallistuu tähän samaan myyttiin menestysteoksessaanZero to One korostamalla, kuinka innovatiivisuus on nimenomaan osa lännen historiaa. Itä sen sijaan edustaa puhdasta toistoa ja kopiointia - itsessään se ei ole kyvykäs synnyttämään mitään uutta (Thiel 2014, 7, 49). Samanlaisen tarinan idästä kertoo myös jo aiemmin viitattu O’Mara. Hänen teoksessaan itä edustaa paitsi luovuuden puutetta myös pahantahtoisuutta. Itä esiintyy O'Maran kirjan viimeisillä sivuilla vastavoimana Piilaaksolle ja sen lupaukselle paremmasta maailmasta (2019, 403-404).

Näiden eurosentristen historiakäsitysten lisäksi on kuitenkin myös kirjallisuutta, jossa Piilaakso tuodaan osaksi kolonialismin historiaa (Pit- 
ti 2018; Ramirez 2007; Spencer 2018). Erityisesti Renya Ramirezin näkökulma on tärkeä. Teoksessa Native Hubs hän keskittyy sekä Kalifornian alkuperäiskansojen hävityksen ja kolonisaation historiaan että nykyisyyteen Piilaakson alueella (2007). Piilaakson alueella, Ramirez tiivistää, vaikuttaa tänä päivänä noin kahdeksankymmentä eri heimoa, jotka yhä taistelevat tyhjän maan fantasiaa vastaan $(2007,38)$.

\section{Yrittäjä/valloittaja}

Modernin ja koloniaalisuuden suhde tarkentuu entisestään, kun tutkitaan innovaatiotalouden sankaritarinoita. Väitänkin, että innovaatiotalouden kirjallisuudessa seikkaileva yrittäjän ja startup-yrittäjän hahmo kierrättää kolonialismin rasistisia sankaritarinoita "uusien maailmojen" valloittamisesta.

Daniel Defoe, Robinson Crusoen kirjoittaja, esitetään usein ensimmäisenä, joka loi teoreettisen pohjan schumpeterilaiselle idealle luovasta, riskejä ottavasta yrittäjästä (Ahmad \& Seymor 2008; Redlich 1949; Reinert 2002). Defoe esitti bisneskirjoituksissaan, että Eurooppaan on syntymässä uusi ihmistyyppi, joka haluaa ottaa riskejä ja koetella epävarmoja tulevaisuuksia (1887). Defoe kehitti termin heijastaja (projector) kuvaamaan tätä uutta spekulatiivista ihannetta. Ei ole välttämättä pelkästään historian sattumaa, että yrittäjämäisen identiteetin kehityksen ratkaisevassa roolissa oli kirjoittaja, joka kehitti myös "prototyyppisen kolonialistisen novellin", jossa valkoinen mies taistelee luontoa ja "villejä" vastaan ja lopulta integroi heidät Euroopan johtamaan maailmankauppaan orjina ja perushyödykkeiden tuottajina (McInelly 2003).

Defoen "heijastajalle" ominainen seikkailijan aura $^{3}$ esiintyy myös Schumpeterin yrittäjähahmossa. Schumpeter halusi siirtyä pois uusklassisesta yrittäjyyden tulkinnasta, jossa yrittäjä on puhdas funktio, joka yhdistää maan, työvoiman ja pääoman tuotantoa varten (Lovio 2009, 10). Tämän sijaan Schumpeter painotti yrittäjien seikkailuhalukkuutta ja innovatiivisuutta: kykyä suuntautua tulevaisuuteen ja synnyttää uusia alkuja. Yhteiskuntia uudistavia riskinottajayrittäjiä ajaa Schumpeterin mukaan kolme motivaatiota: "halu perustaa yksityisiä valtakuntia, halu valloittaa sekä luomisen riemu" $(1983,92)$. Toisaalla Schumpeter kuvaa, kuinka uusien maiden "löytäminen" voidaan nähdä osana yrittäjyyden historiaa sekä kuinka Kolumbuksen matkaa voidaan hyvinkin kutsua yrittäjämäiseksi projektiksi (1939, 8). Tarkasteltaessa Piilaaksoa ja innovaatiotaloutta käsittelevää kirjallisuutta huomaamme, että yrittäjät samaistetaankin usein - positiiviseen tapaan - erilaisiin koloniaalisiin sankareihin.

Yhdysvaltalaisessa innovaatiokirjallisuudessa Piilaakson startup-yrittäjiä kuvataan usein termeillä "cowboy", "lähetyssaarnaaja" (missionary) tai "pioneeri". Nämä kaikki ovat termejä, jotka sitovat Piilaakson yrittäjät osaksi amerikkalaisen asuttajakolonialismin sankarihahmoja. Vaikka esimerkiksi Peter Thiel spekuloi kirjassaan (2016, 70 - 73) sillä, onko löytöretkien loppuminen johtanut myös seikkailuntunteen katoamiseen lännessä, ovat asuttajakolonialismin sankarit selvästi yhä elossa innovaatiotalouden mielikuvissa. Siksi Piilaaksoa kuvaillaan jatkuvasti "villiksi länneksi" (Lewis 1999) ja startup-yrittäjät nähdään "hightech cowboyina ratsastamassa läntiseen aurinkoon" tai katoamassa terra incognitoon (Kenney 2000, 49; O’Mara 2019, 128, 185; Schlaes 2008, 9-12). Sarah Doddin laajaan otantaan perustuva tutkimus yhdysvaltalaisten teknologiayrittäjien omista elämäntarinoista vahvistaa, että yrittäjät näkevät myös itsensä osana "amerikkalaisten pioneerien" (valkoisten asuttajien) historiaa (Dodd 2002, 525 - 526). Analysoimalla yli 150 yrittäjätarinaa Dodd tiivistää keskeisimmät metaforat, joilla yrittäjyyttä kuvataan. Suosituimpia ovat matkaan, purjehtimiseen, darwinistiseen kilpailuun ja sotaan liittyvät metaforat. Doddin mukaan yrittäjien tarinat herättävät myös henkiin Kristoffer Kolumbuksen ensimmäisen matkan kohti Amerikkaa (2002: 526). Tämä alun perin Schumpeterin esittämä ajatus Kolumbuksesta yrittäjänä toistuu myös lukemattomassa määrässä akateemista kirjallisuutta startup-yrittäjyydestä. Esimerkiksi bisnestutkija De Pillis kirjoittaa, kuinka yrittäjyyshenki on iskostunut amerikkalaiseen mentaliteettiin ensimmäisistä siirtokuntalaisista tai ehkä jo Kolumbuksesta alkaen $(1998,6,8)$. Sen sijaan, 
että Kolumbus esitettäisiin yhtenä historian suurimmista rikollisista, joka voitontavoittelun vuoksi käynnisti ekologisen tuhon, alkuperäiskansojen murhaamisen ja orjuuden laajamittaisen historian, hänet kuvataan yrittäjämäisen asenteen esikuvana (Martin 1994) ja Elon Muskin historiallisena edeltäjänä (Carlen 2016, 120-123).

Piilaakson sankarit eivät siis ole ainoastaan tulevaisuuden vaan myös kolonialistisen menneisyyden sankareita. Tämä vahvistaa entisestään Quijanon tulkintaa modernin kolonialistisesta varjosta. Tulevaisuus ottaa näissä tarinoissa teleologisen rakenteen: se on ikuista paluuta menneisyyteen.

\section{Innovaatiotalous valloittamisen muotona: takaisin materiaan}

Innovaatiotaloutta tutkineen Erin McElroyn mukaan innovaatiotalous levittää "asuttajakolonialistisia haluja" (settler desires) (2019). McElroy painottaa, että nämä halut ottavat niin kulttuurisia kuin materiaalisiakin muotoja. Tarkemmin sanottuna, ne ovat samaan aikaan sekä kulttuurisia että materiaalisia. Tämä on myös yksi Quijanon ja Fanonin kaltaisten dekolonialistien keskeisimmistä argumenteista. Esimerkiksi "rotua" tarinana ei voida erottaa maan ja kehojen haltuunoton ja hinnoittelun historiasta. Kolonialismin oloissa "perusta on ylärakenne", kuten Fanon asian ilmaisee. Piilaakson semiokapitalismissa, jossa vuorovaikutus on suoraan arvonmuodostuksen lähde ja vaihdettava hyödyke, erottelu kulttuurin ja materian välillä ei muutenkaan ole välttämättä järkevää.

Kolonialismin ja innovaatiotalouden suhdetta ovat käsitteellistäneet esimerkiksi Nick Couldry ja Ulysses Mejias (2020), joiden mukaan kolonisaatioon on aina kuulunut kollektiivisten resurssien, kuten yhteismaiden, haltuunotto ja yksityistäminen. He esittävät, että vuorovaikutusta, tietoa, ja sosiaalisia suhteita olisi hyvä tarkastella tällaisina kollektiivisina yhteismaina, joita Piilaakson "datakolonialismi" pyrkii yksityistämään. Fyysisistä resursseista, kuten maasta, on Couldryn ja Mejiaksen mukaan siis siirrytty yhä enemmän informaation ja vuorovaikutuksen kolonisaatioon. Couldry ja Mejias kuitenkin si- vuuttavat kolonisaation tärkeimmän historiallisen jatkumon eli maan ja kehon rodullistetun ja sukupuolitetun haltuunoton eurosentristen sivilisaatiokertomuksen: halun asuttaa ja valloittaa. Lähestynkin omassa työssäni innovaatiotalouden materiaalisuutta valloittamisen näkökulmasta kysymällä, kuinka kolonialistiset valloittamisen prosessit kytkeytyvät innovaatiotalouden leviämiseen.

Tästä näkökulmasta käsin huomio kiinnittyy esimerkiksi siihen, kuinka innovaatiotalouden fyysisessä tilassa tapahtuva laajeneminen kytkeytyy rodullistettuihin karkoittamisen prosesseihin. Esimerkiksi innovaatiotalouden urbaaneja keskuksia: San Franciscoa, Oaklandia ja Seattlea tarkastelleet tutkijat ovat huomanneet, että riskipääoman ja teknologiatyön kasautuminen urbaaneille alueille on johtanut massiivisiin ei-valkoisten ja köyhien yhteisöjen karkotuksiin kaupunkialueilta. Anti-Eviction mapping project -nimellä kulkeva tutkimusprojekti on esimerkiksi jäljittänyt, kuinka innovaatiotalouden suhdannevaihtelut korreloivat San Franciscon ja Oaklandin latinoja afroamerikkalaisen väestön häätämisen kanssa (Maharawal 2017; Maharawal \& McElroy 2018). Erin McElroy on tutkinut innovaatiotalouden urbaaneja kolonisaation ja karkottamisen prosesseja Yhdysvaltojen ohella myös Itä-Euroopassa (2019). McElroy ehdottaa, että karkottamista on gentrifikaation sijaan hedelmällistä tarkastella osana asuttajakolonialismin leviämisen historiaa (2019). Omassa tutkimuksessani olen puolestaan tarkastellut samankaltaisia urbaanin karkottamisen prosesseja Israel/Palestiinan innovaatiotalouden keskittymissä (Tarvainen 2021b).

Haltuunoton ja etnisen "puhdistamisen" ohella kolonialistinen valloitus pyrkii aina myös hyödyntämään ja hyväksikäyttämään valloitettuja populaatioita ja alueita. Kolonialismin historiassa valloitettuja alueita onkin usein käytetty laboratorioina pääoman teknologioiden kehittämiseen ja testaamiseen (Jakes 2020; Sharma 2020). Esittelen kaksi esimerkkiä, yhden Navajo-reservaatista Yhdysvalloista ja toisen Palestiinalaisalueilta, näyttääkseni, kuinka kolonisoituja alueita ja populaatioita voidaan jalostaa innovaatiotalouden globaaleiksi laboratorioiksi. 
Navajoihin liittyvä esimerkki liittyy Piilaakson historian merkittävimpänä pidettyyn yhtiöön: Fairchild Semiconductorin. 1960-luvulla yhtiö siirsi intensiivisimpiä mikroprosessorivalmistuksen työvaiheita Navajo-intiaanien New Mexicossa sijaitsevaan reservaattiin (Nakamura 2014). Fairchildin markkinointimateriaaleissa navajonaiset esitettiin ideaalina "esidigitaalisena työvoimana", joka pystyi hyödyntämään "ikiaikaista luovuuttaan" ja "notkeita sormiaan" mikropiirien tuotannossa (Nakamura 2014, 925). Yhdysvallat tuki Fairchildin levittäytymistä alkuperäiskansan alueelle erinäisin verohelpotuksin ja tuin. Lisäksi Fairchild pystyi maksamaan Navajo-työntekijöilleen muita työntekijöitä matalampaa palkkaa, sillä minipalkkavaatimukset eivät Yhdysvalloissa koskeneet reservaattien alueita. Navajo-reservaatilla on merkittävä rooli Piilaakson globalisaatiossa, sillä se toimi laboratoriona teknologiatyön ulkoistamiseen halpatuotantoalueille (Nakamura 2014). Fairchild tulikin 1970-luvulla kuuluisaksi siitä, että se alkoi ensimmäisenä Piilaakson yhtiönä laajamittaisesti ulkoistamaan työtä KaakkoisAasiaan (Henderson 2012). Yhtiö lähti Navajoreservaatista, kun Navajot olivat alkaneet organisoitua parempien työolosuhteiden ja palkkatason vaatimiseksi. "Notkeiden sormien" metafora siirtyi tuotannon mukana Kaakkois-Aasiaan, maalaamaan kuvaa kouluttamattomasta mutta ahkerasta naistyövoimasta, joka "luonnollisesti" on myös halpaa työvoimaa (Nakamura 2014; Rana 2010).

Israelilaiset teknologiayhtiöt käyttävät puolestaan palestiinalaisalueita ase-, valvonta- ja joukkojenhallintateknologian kehittämiseen ja testaamiseen (Halper 2015). Israelilaiset teknologiayhtiöt myös lanseeraavat tuotteita globaaleille markkinoille mainoslauseilla kuten "testattu Gazassa" tai "testattu käytännön taisteluissa" (Machold 2018, 89). Kolonisoitu alue muuttuu näin lisäarvon lähteeksi. Myös yhdysvaltalaiset teknologiajätit, kuten Microsoft, ovat investoineet teknologioihin, joita - lupaa kysymättä - testataan ja kehitetään vallatuilla Palestiinalaisalueilla.

Nämä esimerkit kuvaavat, kuinka innovaatiotalous uusintaa kolonialismin historiasta tuttua logiikkaa, jossa jo kolonisoituja alueita käytetään globalisaation ja pääoman testi- ja kehitysaluei- na. Esimerkit laboratorioista kiinnittävät huomion myös instituutionaalisiin linkkeihin, jotka tuovat valloittamisen instituutiot ja innovaatiot yhteen. Sekä Piilaaksossa että Israelissa, kahdessa innovaatiotalouden johtavassa keskittymässä, innovaatiotalous on täysin riippuvainen sotateollisuuden investoinneista (Senor \& Singer 2009; Weiss 2011). Esimerkiksi Israelissa armeijan tiedusteluyksiköt ovat maan merkittävimpiä startup-hautomoita ja menestyvimmät startupit tulevatkin suoraan näistä yksiköistä. Israelin armeijan teknologinen kyvykkyys rakentuu puolestaan pitkälle Yhdysvaltain sotilasavun varaan. Vaikka kriittinen innovaatiotutkimus usein korostaakin puolustusteollisuuden ja innovaatioiden yhteyttä4, innovaatiotalouden ja valloittamisen yhteyttä ei useinkaan tuoda esiin. Olisi aihetta kysyä, millaisia vaikutuksia on sillä, että innovaatiotalouden johtavat keskittymät sijaitsevat asuttajakolonialististen valtioiden sisällä ja että ne ovat vahvasti linkittyneet näiden valtioiden väkivaltakoneistoon.

Maan valloittamisen ohella koloniaalisuuden näkökulma pakottaa tarkastelemaan myös innovaatiotalouden työnjakoa osana kolonialismin historiaa. Piilaakson ideaalissa kuka vain, joka on "luova" pystyy saamaan rahoitusta ja skaalaamaan innovaationsa globaaleille markkinoille (Florida 2005). Iranin (2018) tutkimus Piilaakson globaalista työnjaosta ja luovuuden ideaalista osoittaa, että "luovuus" on Piilaakson mallissa etukäteen koodattu tarkoittamaan tiettyjen ihmisten mahdollisuutta olla luova. Asiantuntijat, muotoilijat ja markkinoijat löytyvät lännen "luovista kaupungeista", puhelinpalvelukeskukset, elektroniikkateollisuuden kokoonpanotehtaat ja kaivannaisteollisuus globaalista etelästä (Graham \& Thrift 2007, 12; Rana 2010). Kaliforniassa toimivista teknologiayhtiöistä kerätty data osoittaa myös, kuinka johtopaikat keskittyvät voimakkaasti valkoisille, kun taas värilliset kehot työskentelevät pääasiallisesti epäsäännöllisissä, epävarmoissa ja matalasti palkatuissa työtehtävissä. Data Piilaaksoon suuntautuneista pääomasijoituksista puolestaan kertoo voimakkaasti sukupuolittuneista mahdollisuuksista innovoida: esimerkiksi vuonna 2016 vain 2 prosenttia sijoituksista meni 
naisten johtamille teknologiayhtiöille ja startupeille - tämä siitä huolimatta, että naiset johtavat noin 40 prosentia teknologiayhtiöistä (Chang 2019, 7). Jättiyhtiöt kuten Uber ja Amazon ovat puolestaan tulleet tunnetuksi järjestäytymisen vastaisesta lobbauksesta ja epäsäännöllisten "alustamaisten" työolosuhteiden synnyttämisestä. Niin Amazonilla kuin Uberillakin suojaamattomimmat työtehtävät keskittyvät ei-valkoisten työntekijöiden pariin. Elektroniikkateollisuuden ja innovaatiotalouden vaaralliset, matalapalkkaiset ja saastuttavat työvaiheetkin on Piilaakson historiassa 1950-luvulta alkaen keskittyneet erityisesti rodullistetuille naisille (Hossfield 1989, Pellow \& Park 2002). Koloniaalisuuden näkökulmasta katsoen nämä innovaatiotalouden tavat jaotella kehoja ja maantiedettä näyttävät suurten "sivilisaatiokertomusten" itseään toteuttavilta ennustuksilta. Kolonialistinen tarinoiden ja materian verkko vaikuttaa siihen, kuka on "aktiivinen" ja uutta synnyttävä, ja kuka asetetaan toistavaan tai ei-luovaksi nähtyyn työhön.

\section{Kolonialismin tutkimus ja innovaatiotalous: kohti globaalia viitekehystä}

Esimerkit innovaatiokirjallisuudesta havainnollistavat, kuinka näkymättömäksi tekemisen logiikka ja valloittamisen fantasiat kulkevat Schumpeterista Piilaakson tarinoihin. Koloniaalisuuden käsite auttaa myös avaamaan innovaatiotalouteen kytkeytyviä maan ja työn haltuunoton prosesseja. Innovaatiotalous ei tästä näkökulmasta katsoen vaikuta uuden (novus) synnyttäjältä, vaan ennemminkin kolonialististen fantasioiden ja valloittamisen käytäntöjen kierrättäjältä; tavalta luoda kolonialistista aikaa, maantiedettä ja kehoja nykykapitalismin palvelukseen. Ennen kaikkea koloniaalisuuden näkökulma asettaa innovaatiotalouden historialliseen ja globaaliin viitekehykseen.

Kolonialismintutkimus tarjoaa kuitenkin vain yhden hyödyllisen, tosin alihyödynnetyn, tutkimuskirjallisuuden, jonka kautta tarkastella innovaatiotaloutta. Teoreettisesti kiinnostavinta olisi, jos kolonialismintutkimuksen näkökulmia yhdis- tettäisiin muihin kapitalismia ja modernia käsitteellistäviin teorioihin kuten kriittiseen teoriaan. Suuri tarve olisi myös kontekstispesifeille tutkimuksille: innovaatiotalouden ja kolonialismin suhde kun on elävä ja paikassa muuttuva.

ANTTI TARVAINEN on globaalin kehitystutkimuksen tohtorikoulutettava Helsingin yliopistossa.

\section{VIITTEET}

1 Schumpeter mainitsee erikseen seuraavat teokset ydinlähteinään: Fonctions mentales dans les sociétés inférieures (1909), Le surnaturel et la nature dans la mentalité primitive (1931), Mentalité primitive (1921) ja L'ame primitive (1927) (2013: 121)

2 Demior ja Gahoub nostaa seuraavat Islamilaisen keskiajan kirjoittajat keskeiseen rooliin talous- ja yhteiskuntatieteen kehityksessä: Al-Ghazali, Ibn Khaldun, Ibn Taimiyah, Ibn Qayyim, Abu Yousuf, ja Ibn Sina (Avicenna).

3 Ranskankielinen entrepreneur käännettiin englannissa 1800-luvun lopulla juuri "seikkailijaksi".

4 Viittaan tässä esimerkiksi Mariana Mazzucaton tutkimuksiin. 


\section{KIRJALLISUUS}

Ahmad, Nadim \& Seymour, Richard. (2008). ”Defining entrepreneurial activity: Definitions supporting frameworks for data collection". OECD Eurostat.

Appadurai, Arjun \& Alexander, Neta. (2020). Failure. Medford: Polity Press.

Bernardelli, Harro. (1961). "The origins of modern economic theory". Economic Record, 37(79), 320-338.

Bernasconi, Robert (2005). "Lévy-Bruhl among the Phenomenologists: Exoticisation and the Logic of 'the Primitive". Social Identities, 11(3), 229-245.

Berlin, Leslie. (2017). Troublemakers: Silicon Valley's Coming of Age. Simon and Schuster.

Betts, Raymond. F. (1982). ”The French colonial Empire and the French world-view". In Racism and Colonialism (pp. 65-77). Springer, Dordrecht.

Bottici, Chiara. (2009). "Myths of Europe: A theoretical approach". Journal of Educational Media, Memory, and Society, 1(2), 9-33.

Bottici, Chiara \& and Challand, Benoit. (2020). "Europe After Eurocentrism?", Crisis \& Critique 7(1), pp. 56-87.

Carlen, Joe. (2016). A brief history of entrepreneurship: The pioneers, profiteers, and racketeers who shaped our world. Columbia University Press.

Chang, Emily. (2019). Brotopia: Breaking Up the Boys' Club of Silicon Valley. Portfolio.

Challand, Benoit. \& Bottici, Chiara. (2021) "Towards an interstitial Global Theory". Forthcoming in Globalizations, Special issue in Re-imagining Civilization. Taylor \& Francis.

Couldry, Nick., \& Mejias, Ulises. A. (2020). The Costs of Connection: How Data Are Colonizing Human Life and Appropriating It for Capitalism. Stanford University Press.

Daub, Adrian. (2020). What Tech Calls Thinking: an Inquiry into the Intellectual bedrock of Silicon Valley. FSG Originals X Logic.

Dodd, Sarah. D. (2002). "Metaphors and meaning: A grounded cultural model of US entrepreneurship". Journal of Business Venturing, 17(5), 519-535.

De Pillis, Emmeline. G. (1998). "What's achievement got to do with it? The role of national culture in the relationship between entrepreneurship and achievement motivation". Frontiers of entrepreneurship research, 73-87.

Demir, Firat., \& Kaboub, Fadhel. (2009).” Economic Development and the Fabrication of the Middle East as a Eurocentric Project". In The Challenge of Eurocentrism: Global Perspectives, Policy, and Prospects (pp. 77-96). Palgrave Macmillan, New York.

Dussel, Enrique. (1993). "Eurocentrism and modernity (Introduction to the Frankfurt Lectures)". boundary 2, 20(3), 65-76.

Fields, Garry. (2017). Enclosure: Palestinian landscapes in a historical mirror. University of California Press.

Findlay, John. M. (1992). Magic lands: Western cityscapes and American culture after 1940. University of California Press.

Florida, Richard. L. (2005). Cities and the creative class. Psychology Press.

Ghazanfar, Shaikh. M. (1995). ”History of Economic Thought: The Schumpeterian'Great Gap', the'Lost'Arab-Islamic Legacy, and the Literature Gap". Journal of Islamic Studies, 6(2), 234-253.

Graham, Stephen \& Thrift, Nigel. (2007). "Out of order Understanding repair and maintenance". Theory, Culture \& Society, 24(3), 1-25.

Geiger, Susi. (2020). "Silicon Valley, disruption, and the end of uncertainty". Journal of cultural economy" $y, 13(2)$, 169-184.

Henderson, Jeffrey W. (2012). ”The new international division of labour and American semiconductor production in Southeast Asia." in Multinational Corporations and the Third World, by C. Dixon, D. Drakakis-Smith and HD Watts. 91-117

Hosseini, Hamid. S. (2003). "Contributions of medieval muslim scholars to the history of economics and their impact: a refutation of the schumpeterian great gap". In A companion to the history of economic thought, 28-45.

Hossfeld, Karen. J. (1989). Divisions of labor, divisions of lives: Immigrant women workers in Silicon Valley. University of Califoria Press.

Hughes, Thomas. P. (2020). American genesis: a century of invention and technological enthusiasm, 1870-1970. University of Chicago Press.

Irani, Lilly. (2018). ”Design thinking: Defending Silicon Valley at the apex of global labor hierarchies". Catalyst: Feminism, Theory, Technoscience, 4(1).

Jakes, Aaron. G. (2020). Egypt's Occupation: Colonial Economism and the Crises of Capitalism. Stanford University Press.

Kenney, Martin. (2000). Understanding Silicon Valley: The anatomy of an entrepreneurial region. Stanford University Press.

Kerner, Ina. (2018). ”Postcolonial theories as global critical theories". Constellations, 25(4), 614-628.

Leslie, Stuart. W. "How the West Was Won: The Military and the Making of Silicon Valley." Technological Competitiveness: Contemporary and Historical Perspectives on the Electrical, Electronics, and Computer 
Industries. Ed. William Aspray. New York: The Institute of Electrical and Electronics Engineers, Inc (1993): 75-89.

Lovio, Raimo. (2009). "Luova tuho - ikuinen paluu." Tiede \& edistys 34 (2009): 1 - 18.

Maharawal, M. M. (2017). ”San Francisco's Tech-led gentrification." City unsilenced: Urban resistance and public space in the age of shrinking democracy, 30.

Maharawal, Manissa. M. \& McElroy, Erin. (2018). ”The anti-eviction mapping project: Counter mapping and oral history toward bay area housing justice". Annals of the American Association of Geographers, 108(2), 380-389.

Martin, Michael. J. (1994). Managing innovation and entrepreneurship in technology-based firms (Vol. 20). John Wiley \& Sons.

Mendieta, Eduardo, 2001. "Chronotopology: Critique of Spatiotemporal Regimes", pp. 175-197 in William S. Wilkerson and Jeffrey Paris (eds.), New Critical Theory: Essays on Liberation, New York: Rowman \& Littlefield.

McElroy, Erin. (2019). ”Digital Nomads and Settler Desires: Racial Fantasies of Silicon Valley Imperialism”. Imaginations: Journal of CrossCultural Image Studies/Imaginations: revue d'études interculturelles de l'image, 10(1), 215-249.

McElroy, Erin., \& Werth, Alex. (2019). ”Deracinated dispossessions: On the foreclosures of "gentrification" in Oakland, CA". Antipode, 51(3), 878-898.

McInelly, Brett. C. (2003). "Expanding Empires, Expanding Selves: Colonialism, the Novel, and Robinson Crusoe". Studies in the Novel, 35(1), 1-21.

Nakamura, Lisa. (2014). "Indigenous circuits: Navajo women and the racialization of early electronic manufacture”. American Quarterly, 66(4), 919-941.

O'Mara, Margaret. (2019). The code: Silicon Valley and the remaking of America. Penguin Books.

Pellow, David \& Park, Lisa. S. H. (2002). The Silicon Valley of dreams: Environmental injustice, immigrant workers, and the high-tech global economy (Vol. 31). NYU Press.

Pitti, Stephen J. 2003. The Devil In Silicon Valley: Northern California, Race, and Mexican Americans. Princeton: Princeton University Press

Quijano, Anibal. (2007). "Coloniality and modernity/ rationality". Cultural studies, 21(2-3), 168-178.

Rana, Shruti. (2010). "Fulfilling Technology's Promise: Enforcing the Rights of Women Caught in the Global High-Tech Underclass". In Women, Science, and Technology (pp. 336-356). Routledge.

Ramirez, Renya. K. (2007). Native hubs: Culture, community, and belonging in Silicon Valley and beyond. Duke University Press
Redlich, Fritz. (1949). "The origin of the concepts of" Entrepreneur" and" Creative entrepreneur". Explorations in Economic History, 1(2), 1.

Reinert, Erik. S. (2002). "Schumpeter in the context of two canons of economic thought". Industry and Innovation, 9(1-2), 23-39.

Saxenian, Annalee. (1983). ”The genesis of silicon valley". Built Environment (1978-), 7-17.

Schlaes, Amity (2008). "From the Ponderosa to the Googleplex: How Americans match money to ideas". E-journal USA. Volume 13, num. 15. US Department of state.

Schumpeter, Joseph. A. (1939). Business Cycles, 2 vol., McGraw-Hill, New York

Schumpeter, Joseph. A. (2003). Capitalism, socialism \& democracy. Taylor and Francis.

Schumpeter, Joseph. A. (1983). The theory of economic development. New Brunswick. NJ Transactions Books Reprint.

Sharma, Nandita. (2020). Home Rule. Duke University Press.

Spencer, K. A. (2019). A People's History of Silicon Valley. Eyewear Publishing.

Tarvainen, Antti.I. (2021). Colonial temporalities of innovation. Forthcoming in Globalizations, special issue for Re-Imagining Civilization. Taylor \& Francis.

Tarvainen, Antti. I. (2021b). "Settler Colonialism dresses in Silicon: alternatives to Margaret O’Maras enclosed histories". Forthcoming in Prometheus journal.

Thiel, Peter. A., \& Masters, B. (2014). Zero to one: Notes on startups, or how to build the future. Currency.

Veracini, Lorenzo. (2008). "Settler collective, founding violence and disavowal: The settler colonial situation". Journal of Intercultural Studies, 29(4), 363379.

Veracini, Lorenzo. (2011). "Introducing: Settler colonial studies". Settler colonial studies, 1(1), 1-12.

Weiss, Linda. (2014). America Inc.?: innovation and enterprise in the national security state. Cornell University Press.

Wolfe, Patrick. (2012). "Purchase by other means: The Palestine Nakba and Zionism's conquest of economics”. Settler Colonial Studies, 2(1), 133-171. 